\title{
MK801 impairs acquisition and expression of conditioned responses in the rabbit nictitating membrane preparation
}

\author{
JAIMIE COX, RACHEL GUTHRIE, MICHAELA MACRAE, and E. JAMES KEHOE \\ University of New South Wales, Sydney, Australia
}

\begin{abstract}
MK801 is a noncompetitive antagonist to $N$-methyl-D-aspartate (NMDA) receptors. MK801 $(0.1 \mathrm{mg} / \mathrm{kg}$ IV) was given to rabbits during classical conditioning of their nictitating membrane response. Administration of MK801 before each training session impaired acquisition of a conditioned response (CR). When MK801 administration was suspended, responding remained at a low level. Control animals were given either MK801 after each training session (Experiment 1) or saline before each session (Experiment 2). The control animals showed high levels of CR acquisition. When the control animals were given the MK801 before a session, they showed a large deficit in responding. Responding returned to its former level when the original control condition was reinstated. In all the animals, tests for motor deficits caused by MK801 proved negative; the magnitude of the UR was not influenced by MK801 at either the beginning or end of training. In conclusion, it appears that MK801 impairs both the formation of associative linkages and the performance of established CRs. A reduction in CS salience caused by MK801 is the most parsimonious explanation of the data. There is a more complex, two-factor alternative that contends that MK801 directly hindered associative formation in the subjects trained with that drug and produced a state-dependent generalization decrement in responding when introduced to the control subjects.
\end{abstract}

MK801 is a noncompetitive antagonist to $N$-methyl-Daspartate (NMDA) receptors (Kemp, Foster, \& Wong, 1987). These NMDA receptors appear to play a role in the facilitation of synaptic transmission that is induced by neural activity. For example, antagonists to NMDA receptor function, such as AP5 and MK801, have blocked the induction but not the expression of long-term potentiation (LTP) of synaptic transmission (Gilbert \& Mack, 1990; Muller, Joly, \& Lynch, 1988). The synaptic mechanisms of LTP may be a neural substrate of associative learning, which has long been thought to rely on activityinduced changes in the efficacy of synaptic transmission (Hebb, 1949, p. 50). For example, classical conditioning of the rabbit's nictitating membrane (NM) is correlated with an LTP-like increase in the amplitude of the perforant path-granule cell population spike (Weisz, Clark, \& Thompson, 1984). Furthermore, the induction of LTP facilitates classical conditioning of the NM response (T. W. Berger, 1984). On the basis of such findings, NMDA receptors have been implicated in associative learning (Collingridge, Kehl, \& McLennan, 1983; Cotman \& Iversen, 1987; Lynch et al., 1990; Morris, Davis, \& Butcher, 1990). In particular, the NMDA receptor is

Preparation of this manuscript was supported by Australian Research Council Grant AC9231222. The authors thank Amanda J. Horne for her assistance in preparing the manuscript. Correspondence should be sent to E. J. Kehoe, School of Psychology, University of New South Wales, P.O. Box 1, Kensington, NSW 2033, Australia. thought to act as a "conjunction device" that increases synaptic efficacy where pre- and postsynaptic inputs converge. It follows that antagonists of NMDA receptors, such as MK801, should impair associative learning.

There is a growing body of experimentation aimed at testing whether and how MK801 impairs learning. Although the hypothesis is simple, testing it has been problematic. Any attempt to determine the impact of a drug on learning must take into account the long-standing distinction between "learning" and "performance" (Gormezano, Kehoe, \& Marshall, 1983; Wroblewski \& Danysz, 1989). This distinction recognizes that the expression of past experience in overt behavior depends on other factors - for example, attention, motivation, and fatigue. For instance, some deficits in learned behavior caused by MK801 can be attributed to a motor deficit (Keith \& Rudy, 1990). Moreover, drugs can indirectly affect associative learning by altering the sensory processing of the conditioned stimulus (CS) and/or the unconditioned stimulus (US). In the NM preparation, for example, $d$-lysergic acid diethylamide (LSD) increases the rate of CR acquisition, lowers the minimum intensity of the CS that elicits CRs (Gormezano \& Harvey, 1988), and lowers the minimum intensity of the US that evokes a UR (Harvey, Gormezano, Cool-Hauser, \& Schindler, 1988). Conversely, haloperidol (Harvey \& Gormezano, 1981), morphine (Schindler, Gormezano, \& Harvey, 1984), and scopolamine (Harvey, Gormezano, \& CoolHauser, 1983) retard CR acquisition and raise the threshold intensity of the CS for CR elicitation. 
The present experiments were undertaken to delineate the effects of MK801 on classical conditioning in the rabbit nictitating membrane (NM) preparation. The rabbit NM preparation was selected for three reasons. First, at a behavioral level, it is well established as an exemplar of associative learning (e.g., Gormezano et al., 1983). Second, the rabbit NM preparation is one of the most widely used preparations for the neurophysiological study of associative learning in mammals (Gabriel, 1988; Gormezano, Thompson, \& Prokasy, 1987; Thompson, 1976). Third, there is a well-established battery of behavioral tests for psychopharmacological studies using the rabbit NM preparation (Gormezano \& Harvey, 1980; Gormezano et al., 1983).

Since the present experiments were run, G. B. Robinson and his associates have published reports concerning the effects of MK801 on conditioning in the rabbit NM preparation (G. B. Robinson, 1993; G. B. Robinson, Port, \& Stillwell, 1993). Their experiments have revealed that administration of MK801 $(.05$ or $.10 \mathrm{mg} / \mathrm{kg}$, s.c.) during CS-US training impaired CR acquisition in a dose-dependent fashion. When MK801 was suspended for 4 of the most impaired rabbits, there was no evidence of either an immediate increase in the level of responding to the CS, or savings during the subsequent CS-US training (G. B. Robinson, 1993). MK801 also impaired the performance of established CRs. Specifically, G. B. Robinson et al. administered both $0.05-$ and $0.10-\mathrm{mg} / \mathrm{kg}$ doses to control rabbits that received their training under saline. The $0.10-\mathrm{mg} / \mathrm{kg}$ dose, but not the $0.05-\mathrm{mg} / \mathrm{kg}$ dose, reduced responding by approximately $30 \%$. However, G. B. Robinson (1993) failed to replicate this reduction with the $0.10-\mathrm{mg} / \mathrm{kg}$ dose. Finally, MK801 impaired performance of the UR. Within-subjects comparisons revealed that the size of the UR was reduced up to $30 \%$ by MK801 in a dose-dependent fashion (G. B. Robinson, 1993; G. B. Robinson et al., 1993).

\section{EXPERIMENT 1}

Experiment 1 was aimed at identifying associative and sensorimotor effects of MK801 in the rabbit NM preparation. Rabbits in the experimental group were given MK801 before each of a series of training and test sessions. In brief, the series included assessments of (1) sensorimotor function by examining the unconditioned response (UR) across different intensities of the US and across different CS-US intervals, (2) CR acquisition during successive sessions of CS-US pairings, and (3) CR performance after suspension of MK801 before the session. As a contrast to the experimental group, another group of rabbits received MK801 after each test session. This group controlled for nonspecific, chronic effects of MK801, including, for example, any neural damage, disruption of any memory consolidation, and/or tolerance to the drug.

The dose level of MK801 was $0.10 \mathrm{mg} / \mathrm{kg} \mathrm{IV}$, which was the same nominal dose that had showed the greatest effect in G. B. Robinson's research. The dose was chosen because it (1) impairs the induction of hippocampal long-term potentiation in the conscious rabbits (G. B. Robinson \& Reed, 1992) and rats (Gilbert \& Mack, $1990),(2)$ does not have a primary hypoalgesic effect that may impair sensory processing of the US (Trujillo \& Akil, 1991; Venable \& Kelly, 1990), and (3) has disrupted spontaneous alternation of instrumental choice behavior in mice (Parada-Turska \& Turski, 1990), spatial learning in rats (Heale \& Harley, 1990; G. S. Robinson, Crooks, Shinkman, \& Gallagher, 1989; Shapiro \& Caramanos, 1990), and classical conditioning in fish (Xu \& Davis, 1992).

Although the procedure of Experiment 1 paralleled those of G. B. Robinson and his associates in many ways, there were some differences. First, the control condition in Experiment 1 entailed the injection of MK801 after the training session rather than saline before the session. Second, the drug was injected intravenously rather than subcutaneously. Moreover, training was begun no more than $45 \mathrm{~min}$ after injection, rather than the 75-min period that was used by G. B. Robinson. With respect to behavioral training, we used an electrotactile US rather than an airpuff US. Finally, in order to measure potentiation of activity in hippocampal dentate granule cells, G. B. Robinson (1993) also applied electrical stimulation to the perforant path during both the $\mathrm{CS}$ and the intertrial interval. In the present experiments, training entailed only CS and US presentations without electrical brain stimulation.

\section{Method}

Subjects. We used 16 female albino rabbits (Oryctolagus cuniculus). On arrival from the university's breeding unit, they were $70-80$ days old and weighed approximately $1.5 \mathrm{~kg}$. All the rabbits were individually housed and had free access to food and water.

Apparatus. The apparatus and recording procedure for the NM response were patterned after those of Coleman and Gormezano (1971), who detail modifications of those described by Gormezano (1966). In brief, each subject was restrained in a Perspex box and trained individually in one of eight conditioning chambers. In each chamber, a speaker was mounted $8 \mathrm{~cm}$ anterior to and $16 \mathrm{~cm}$ above the subject's head. The speaker provided an auditory CS, which was an $800-\mathrm{msec}, 94-\mathrm{dB}$ (SPL), $1000-\mathrm{Hz}$ pure tone superimposed on an ambient noise level of $82 \mathrm{~dB}$ that was provided by an exhaust fan. An 8-W neon light tube was mounted $4 \mathrm{~cm}$ above the speaker. The US was a $50-\mathrm{Hz}$ ac electrical current delivered via stainless steel Autoclip wound clips, positioned $10 \mathrm{~mm}$ apart and $15 \mathrm{~mm}$ posterior to the lateral canthus of the right eye. The stimulus events and response recording were controlled by an Apple II computer that was equipped with interfaces and software developed by Scandrett and Gormezano (1980).

To transduce movements of the NM, a small hook was attached to a silk loop sutured into the NM of the rabbit's right eye. The hook was connected to one end of an L-shaped crank. Inside a light-proof cylinder, movement of the crank rotated a disk of polarized filter, which was interposed between a light-emitting diode and a phototransistor covered by a fixed polarized filter. Thus, rotation of the disk produced changes in the intensity of light reaching the phototransistor through the fixed filter (Gormezano \& Gibbs, 1988). The signal from the phototransistor was amplified and transmitted to an analog-to-digital converter (10-msec sample rate) mounted in the computer. 
Procedure. All the rabbits received 1 day of preparation, 2 days of recovery, 1 day of adaptation, and 12 days of training and testing. On the preparation day, hair surrounding the rabbit's right eye was removed, the eye was anesthetized with proxymetacaine hydrochloride (Opthaine), and a small loop of surgical silk (000 Dynex) was sutured into the NM. On adaptation day, the animals were placed into the conditioning apparatus for $60 \mathrm{~min}$, but no substances were injected nor were any stimuli presented. Following adaptation, the rabbits were randomly assigned to one of two drug conditions $(n=8)$, designated Groups MK and CON. Unless otherwise specified, Group MK was injected with MK801 $(0.1 \mathrm{mg} / \mathrm{kg} \mathrm{IV})$ in a marginal ear vein $30-45 \mathrm{~min}$ before each session. Group CON received the same dose of MK801 within $15 \mathrm{~min}$ after the session.

On Day 1, all the animals received 70 presentations of a 50 msec US with intensities of $0.1,0.25,0.5,0.75,1.0,2.0$, and $3.0 \mathrm{~mA}$ in ascending and descending orders of intensity. There was an equal number of ascending and descending series.

On Day 2, all the animals received 66 CS-US trials. Each block of trials contained a $100-\mathrm{msec}$, 2-mA US-alone trial, and five CS-US pairings with a CS duration of $100 \mathrm{msec}$. The CS-US intervals were $0,100,200,400$, or $800 \mathrm{msec}$. One trial using each interval was presented at random within each block.

Starting with Day 3, all the rabbits received 8 days of training. Each session had 60 CS-US pairings and six nonreinforced presentations of the CS. On paired trials, the CS duration was $800 \mathrm{msec}$, the CS-US interval was $800 \mathrm{msec}$, and the US was $3 \mathrm{~mA}$ in intensity and $100 \mathrm{msec}$ in duration.

On Day 11 , all the animals received a training schedule that was identical to that used on Days 3-10. However, the time of MK801 injection was reversed. Group MK was injected with MK801 after their training session, and Group CON received MK801 before their training session. On Day 12, Groups $\mathrm{MK}$ and $\mathrm{CON}$ received injections at their usual times. Throughout the experiment, the mean intertrial interval (ITI) was $60 \mathrm{sec}$ (range $=40-50 \mathrm{sec}$ ).

Response definition. A CR was defined as any extension of the NM exceeding $0.5 \mathrm{~mm}$ initiated during the $800-\mathrm{msec}$ duration of the CS (Marshall-Goodell, Schreurs, \& Gormezano, 1982).

\section{Results}

Initial US-UR. To detect any motor effects caused by MK801, the NM extensions following US-alone presentations were analyzed by using three alternative scoring procedures. First, "UR magnitude" was defined as the largest NM extension initiated within $400 \mathrm{msec}$ after US onset. If no extension occurred, a " 0 " was scored and was included in the analysis. Second, "UR amplitude" was defined as the largest NM extension, but included only those extensions that exceeded a minimum criterion of $0.5 \mathrm{~mm}$. Third, "UR likelihood" was the proportion of US-alone trials in which the NM extension exceeded a 0.5-mm criterion (Marshall-Goodell, Kehoe, \& Gormezano, 1992). As will be detailed below, all three analyses revealed systematic effects of US intensity, but yielded no discernible effect of MK801's time of injection.

Figure 1 shows the magnitude of URs as a function of US intensity for Groups MK and CON. Inspection of Figure 1 reveals that UR magnitude increased steadily as US intensity increased. URs were close to zero for the three lower intensities, but rose dramatically for the stronger intensities. Averaging across groups, the mean UR magnitudes for the $0.1-, 0.25-, 0.5-, 0.75-, 1.0-, 2.0-$, and $3.0-\mathrm{mA}$ intensities were $0.1,0.1,0.1,2.2,3.1,4.5$, and

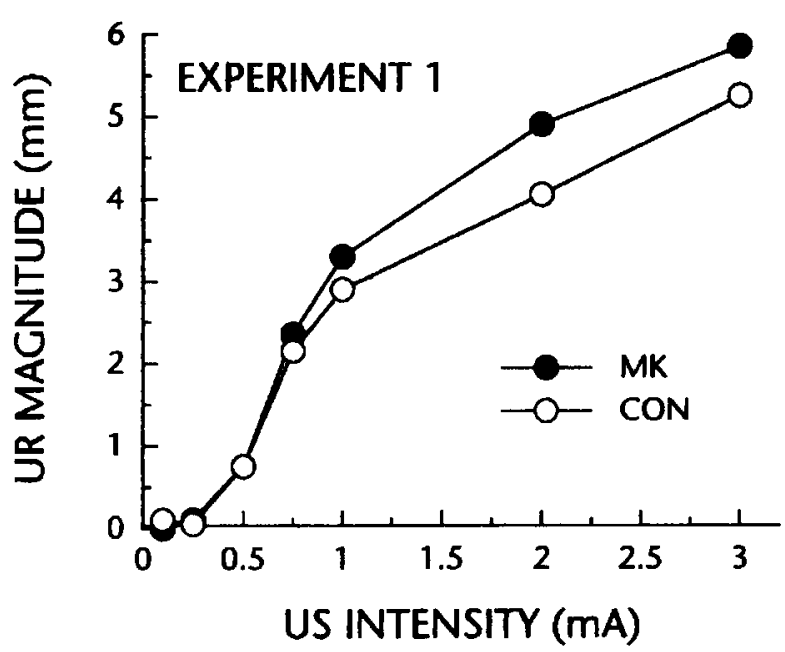

Figure 1. The mean magnitude of URs as a function of US intensity for Groups MK and CON in Experiment 1.

$5.6 \mathrm{~mm}$, respectively. The UR magnitudes in Group MK tended to be slightly larger than those of Group CON at the higher US intensities.

Statistical analyses confirmed that US intensity had a significant main effect on UR magnitude [linear trend $F(1,14)=56.98, p<.01]$. Any apparent differences between Groups MK and CON were not significant $(F \mathrm{~S}<1)$. The analyses of UR likelihood and UR amplitudes yielded parallel results. Specifically, US intensity had significant main effects on both UR amplitude and UR likelihood [linear trend $F_{\mathrm{s}}(1,14)=47.83$ and 41.16, respectively, $p<.01]$. Any apparent differences between the two groups were small, unsystematic, and nonsignificant.

An analysis of UR magnitude was also conducted for the procedure on Day 2, in which the US was preceded by the CS at five different CS-US intervals. As was seen on Day 1, differences between the two groups were small, unsystematic, and nonsignificant $(F \mathbf{s}<1)$. Apparent differences across the CS-US intervals were also small and unsystematic $(F \mathrm{~s}<1)$.

CR acquisition. Figure 2 shows the percentage of CRs over the days of CS-US training. Inspection of Figure 2 reveals that responding in Group MK never increased, but hovered around 3\% CRs throughout training. In contrast, responding in Group CON rose rapidly over the first 4 days to $67 \% \mathrm{CRs}$, then tapered off to $77 \%$ CRs. Statistical analyses confirmed that the overall difference between Groups MK and CON was significant $[F(1,14)=62.70, p<.01]$. Examination of the data from individual subjects revealed that only 2 subjects in Group MK showed any evidence of $\mathrm{CR}$ acquisition. Specifically, they showed $12 \%$ and $19 \%$ CRs on the last day. In contrast, all the subjects in Group CON achieved levels of $50 \%$ CRs or greater.

Reversal of administration time. Figure 3 shows the effects of reversing the time of MK801 injection on Day 11. Specifically, Figure 3 shows the mean percentage of CRs for all of Day 10, three blocks of 20 trials in 


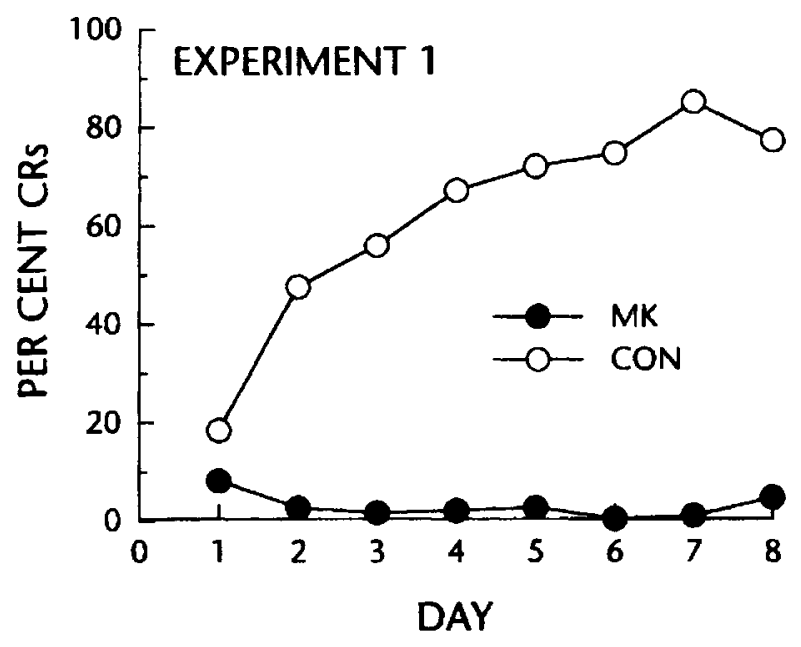

Figure 2. The mean percentage of CRs over days of CS-US training for Groups MK and CON in Experiment 1.

Day 11, and three blocks of 20 trials in Day 12. The data from the sessions on Days 11 and 12 are divided into three consecutive blocks of trials in order to reveal any trends within those sessions.

Inspection of Figure 3 reveals that responding in Group MK rose slightly on Day 11, when MK801 was not administered until after the training session. Specifically, the mean level of responding increased from $5 \%$ CRs on Day 10 to 23\% CRs in the first block of Day 11 . During the second and third blocks, responding remained elevated at mean levels of $20 \%$ and $19 \%$ CRs, respectively. This apparent elevation, however, failed to achieve even a liberal level of statistical significance $[F(1,14)=2.61, p>.10]$. Examination of the data from the individual subjects revealed that the elevation in responding could be attributed to 2 of the 8 subjects.

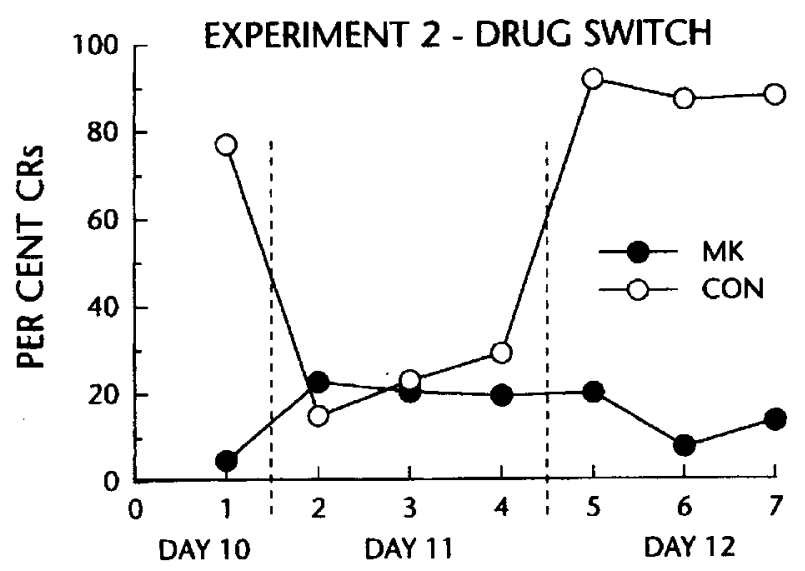

TRIAL BLOCK

Figure 3. The effects of reversing the time of $\mathrm{MK801}$ injection on Day 11. The figure shows the mean percentage of CRs for all of Day 10, three blocks of 20 trials in Day 11, and three blocks of 20 trials in Day 12 for Groups MK and CON in Experiment 1.
Those 2 subjects were the same animals in Group MK that had shown evidence of CR acquisition by Day 10 . Within the first block of CS-US trials on Day 11, they achieved $69 \%$ and $77 \%$ CRs, respectively. Among the other 6 subjects, none had shown any previous CR acquisition, and they displayed no increase in responding. On Day 12, when MK801 injection was reinstated before the session, responding in the 2 subjects that had shown CR acquisition on Day 11 persisted, but fell to levels around $45 \%$ CRs. Thus, responding in Group MK as a whole fell slightly to mean levels of less than $20 \%$ CRs.

In Group CON, responding decreased sharply when MK801 was injected before the session on Day 11 . Specifically, mean levels of responding in Group CON decreased from $77 \%$ CRs on Day 10 to $12 \%$ CRs in the first block of Day $11[F(1,14)=30.60, p<.05]$. Responding was abolished in 7 of the 8 subjects. The remaining subject continued responding at or near $100 \%$ CRs. Responding recovered slightly during the second and third blocks of Day 11, reaching mean levels of $23 \%$ and $29 \%$ CRs, respectively. On Day 12, when MK801 injection was returned to the end of the session, responding to the CS recovered completely to mean levels around $90 \% \mathrm{CRs}$ for all the subjects. These levels were significantly greater than those on Day $11[F(1,14)=$ $54.07, p<.01]$.

\section{Discussion}

Experiment 1 revealed that the administration of MK801 before a training session nearly abolished CRs in both Groups MK and CON. The deficit in CR acquisition in Group MK confirmed a deficit seen by G. B. Robinson (1993). Likewise, the deficit in CR performance in Group CON confirmed similar deficits seen by G. B. Robinson et al. (1993; but see G. B. Robinson, 1993). The deficits in Experiment 1 were greater than those seen previously with the $0.10-\mathrm{mg} / \mathrm{kg}$ dose, which may reflect the more direct route of injection and/or the shorter waiting period between injection and training session. The only major divergence between present and previous findings concerns the effects of MK801 on the UR. When measured at the start of Experiment 1, the UR was unaffected by MK801. In contrast, measurements at the end of training by G. B. Robinson and his associates showed a reduction in the UR, caused by MK801.

In order to explain the deficits in CR acquisition and performance, the results of Experiment 1 rule out nonspecific deficits and disruption of memory consolidation by MK801. All the subjects received the same dose and number of MK801 injections. Hence, the massive differences between Groups $\mathrm{MK}$ and $\mathrm{CON}$ that were caused by time of the injection indicates that the CR deficits did not arise from some nonspecific, deleterious effect of MK801. In other words, the action of MK801 was relatively short acting and needed to be present during the training sessions. This finding converges with observations by G. B. Robinson et al. (1993), who found that injection of MK801 (.10 mg/kg, s.c.) for 4 days 
prior to CS-US training failed to have any discernible effect on CR acquisition. Finally, the substantial CR acquisition seen in Group CON suggests that any longterm memory consolidation after a training session is little affected by MK801. Although the present experiment did not include a vehicle-only group, the course of $C R$ acquisition in Group CON appeared to be the same as that in dozens of undrugged and saline-control groups run in our laboratory and elsewhere under similar parameters (Gormezano \& Harvey, 1980; Harvey \& Gormezano, 1982; Kehoe, 1986; Kehoe \& Graham, 1988; G. B. Robinson et al., 1993).

\section{EXPERIMENT 2}

Experiment 2 was conducted to confirm and refine the findings of Experiment 1. Specifically, the experiment contained the following key features: (1) a replication of the US intensity manipulation on Day 1, (2) a replication of the CS-US-UR reflex modification procedure that failed in Experiment 1, (3) training with a light CS as well as a tone CS to determine whether or not the effects of MK801 were specific to the auditory sensory system, (4) interspersed tests with a compound of the tone plus light to assess both sensory processing and the summation of any subthreshold CR tendencies, (5) a temporary suspension in the administration of MK801 to determine whether or not any underlying associative strength was masked by the drug, (6) further tests with the US to determine whether there had been any change in the effect of MK801 on the UR over the course of training and repeated injections, and (7) a test in which the intensity of the tone was varied to assess the processing of the CS. In addition to these features of the behavioral testing, the control group received a saline injection before each training session rather than MK801 after the session. After the CRs were established in the control group, they were tested under MK801 to determine whether MK801 would again depress CR performance. As may be apparent, several features of the present experiment paralleled procedures used by G. B. Robinson and his associates, particularly tests with the US at the end of training and the use of a saline control group.

\section{Method}

Subjects. We used 16 female albino rabbits.

Apparatus and Procedure. Except where indicated, the apparatus and procedure were identical to those used in Experiment 1 . A light $\mathrm{CS}$ was provided by flashing the houselight at $20 \mathrm{~Hz}$ for $800 \mathrm{msec}$. All the rabbits received 1 day of preparation, 2 days of recovery, 1 day of adaptation, and 18 days of testing and training. As in Experiment 1, the rabbits were randomly assigned to two groups $(n=8)$, designated as Groups MK and SAL. Except for 2 days with a drug-reversal test, Group MK was injected with MK801 (0.1 mg/kg IV), and Group SAL was injected with a corresponding volume of saline $30-45 \mathrm{~min}$ before each session.

On Day 1 , all the animals received 70 US-alone trials. In each of 10 blocks, the USs were $0.1,0.25,0.5,0.75,1.0,1.5$, and $2.0 \mathrm{~mA}$ in intensity. The USs were presented in both ascending and descending orders of intensity. On Day 2, all the animals received 6 blocks of trials, each containing 1 US-alone trial, 5 tone-US pairings, and 5 light-US pairings. On the tone-US and light-US trials, the CS-US intervals were $0,100,200,400$, or $800 \mathrm{msec}$. The CS duration equaled the CS-US interval. Trial types were presented in a random order within each block.

Starting with Day 3, Groups MK and SAL received 8 days of training. Each session consisted of 30 tone-US pairings $(T+), 30$ light-US pairings $(\mathrm{L}+$ ), and 6 nonreinforced tests of the light and tone presented as a compound (TL-). Trials were presented in blocks, in which $5 \mathrm{~T}+$ and $5 \mathrm{~L}+$ trials were randomly interspersed. Every 11 th trial was a TL - trial. During Days 11-14, all the animals received 2 days of training in which their drug schedules were reversed. Group MK received an injection of saline, and Group SAL received MK801. On the remaining 2 days, the groups were returned to their original regimes. Half of each group experienced drug reversal on Days 11 and 14. For the other half, the drug conditions were reversed on Days 12 and 13.

On Days 15-17, all the animals received 3 days of training in a schedule consisting of $30 \mathrm{~T}+$ trials, $30 \mathrm{~L}+$ trials, and $12 \mathrm{US}$-alone trials. Each block of trials contained randomized presentations of $6 \mathrm{~L}+, 6 \mathrm{~T}+$, and 2 US-alone trials. The mean ITI was $60 \mathrm{sec}$ (range $=40-50 \mathrm{sec}$ ).

On Day 18, the animals received the usual $30 \mathrm{~T}+$ and $30 \mathrm{~L}+$ trials plus $12 \mathrm{~T}$-alone test trials. On the T-alone trials, the tone intensity was varied across values of 94,99 , and $104 \mathrm{~dB}$.

\section{Results}

As a result of illness, 2 subjects were removed from the experiment, 1 from Group MK on Day 15 and 1 from Group SAL on Day 11. Their data, however, are included in the results up until their illnesses.

Initial US-UR. Figure 4 shows the magnitude of URs as a function of US intensity for Groups MK and SAL. As seen in Experiment 1, UR magnitude increased steadily as US intensity increased [linear trend $F(1,14)=$ $117.37, p<.05]$. Averaging across groups, the mean UR magnitudes for the $0.1-, 0.25-, 0.5-, 0.75-, 1.0-, 1.5-$, and $2.0-\mathrm{mA}$ intensities were $0.0,0.3,1.2,2.5,3.7,5.3$, and $6.1 \mathrm{~mm}$, respectively. At all US intensities, UR magnitudes appeared slightly greater for Group SAL than for Group MK. However, this and any other apparent differences between Groups MK and SAL did not even approach significance $\left(F_{\mathrm{s}}<1\right)$.

On Day 2, the mean magnitude of the UR to a 2-mA US in Group MK $(M=3.8 \mathrm{~mm})$ again appeared smaller than that of Group SAL $(M=5.6 \mathrm{~mm})$. Once again, however, this difference was not significant, even by a liberal criterion $[F(1,14)=1.54, p>.10]$. For trials on which the CS preceded the US, there was no evidence that the tone CS facilitated the UR in Group MK, but there was some evidence of facilitation in Group SAL. Specifically, in Group MK, for the CS-US intervals of $0,100,200,400$, and $800 \mathrm{msec}$, the mean UR magnitudes were $3.7,4.0,3.6,3.8$, and $3.9 \mathrm{~mm}$, respectively. None of these were significantly larger than that of USalone trials (all $F \mathrm{~S}<1$ ). In Group SAL, however, the corresponding mean UR magnitudes were 6.0, 6.5, 6.3, 6.3, and $6.4 \mathrm{~mm}$, respectively. With the exception of the 0 -msec CS-US interval, these means were all significantly greater than that of the US-alone trials $[M=$ $5.6 \mathrm{~mm}$; smallest $F(1,14)=5.58, p<.05]$. For the light 


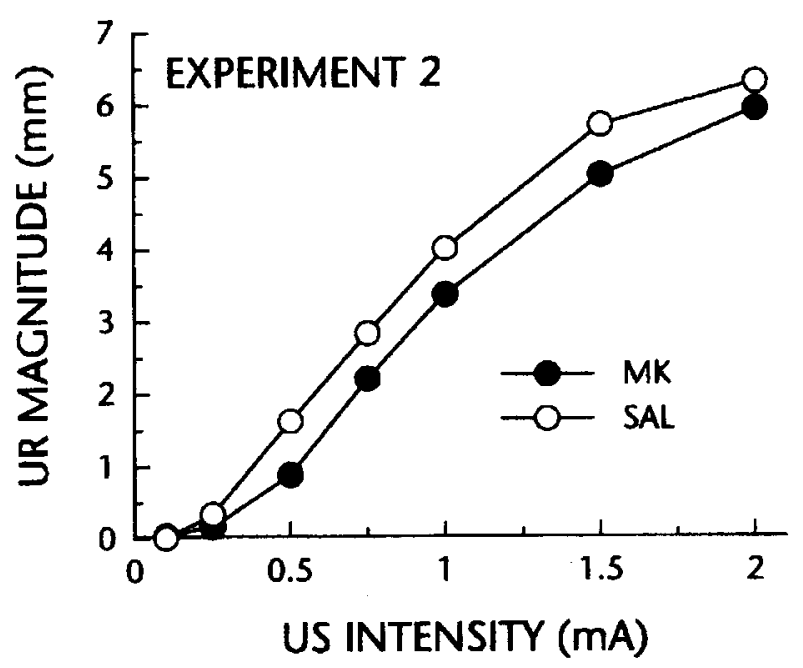

Figure 4. The mean magnitude of URs as a function of US intensity for Groups MK and SAL in Experiment 2.

CS, there was no discernible modification of the UR in either group. At all CS-US intervals for the light, the UR magnitude was never more than $0.1 \mathrm{~mm}$ greater than on US-alone trials (all $F \mathrm{~s}<1$ ).

CR acquisition. Figure 5 shows the percentage of CRs over days. Examination of Figure 5 reveals that, in Group MK, responding on $\mathrm{T}+$ and $\mathrm{L}+$ trials rose gradually but significantly and achieved mean levels of around $30 \%$ CRs by the end of training [linear trend $F(1,14)=10.94, p<.01]$. Examination of data from individual subjects in Group MK revealed substantial

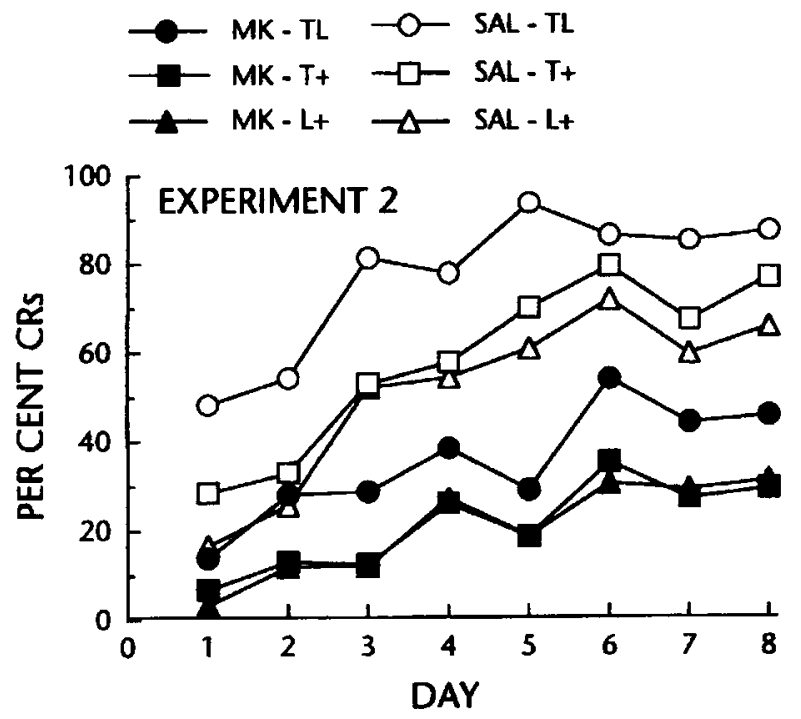

Figure 5. The mean percentage of CRs over days of training with pairings of a tone $C S$ with the $U S(T+)$, pairings of a light CS with the US $(L+)$, and test trials of a tone and light compound (TL-) for Groups MK and SAL in Experiment 2. variation among them. Specifically, 3 of the 8 subjects showed CR acquisition that exceeded $50 \%$ CRs on $\mathrm{T}+$ and $\mathrm{L}+$ trials. Three subjects showed low but discernible $\mathrm{CR}$ acquisition, achieving levels between $10 \%$ and $50 \%$ CRs. In the subjects that showed any CR acquisition, summation was also evident. That is, responding on TL trials was higher than on either the $\mathrm{T}+$ or $\mathrm{L}+$ trials. The 2 remaining subjects responded at negligible levels on $\mathrm{T}+, \mathrm{L}+$, and $\mathrm{TL}-$ trials $(<10 \% \mathrm{CRs})$. Thus, in those subjects, no otherwise hidden responding was exposed by combining the two CSs.

In Group SAL, responding on $\mathrm{T}+$ and $\mathrm{L}+$ trials rose rapidly and stabilized at mean levels around $70 \%$ CRs $[$ linear trend $F(1,14)=64.00, p<.01]$. Inspection of the data from individual subjects revealed that all of them reached levels greater than $50 \%$ CRs. Throughout training, responding on TL- trials was even greater, reaching mean levels around $90 \% \mathrm{CRs}$. All the subjects attained levels of $100 \%$ CRs on some days.

Statistical comparisons confirmed that the rate of CR acquisition in Group MK was slower than that of Group SAL $[F(1,14)=11.01, p<.01]$. These comparisons also confirmed that Groups MK and SAL differed significantly in their overall mean CR levels on $\mathrm{T}+, \mathrm{L}+$, and $\mathrm{TL}$ - trials $\left[F_{\mathrm{s}}(1,14)=51.15,39.64,81.54 ; p \mathrm{~s}<.01\right]$.

Reversal of MK801 and saline. Figure 6 shows the mean percentage of CRs during Days 11-14 for Groups MK and SAL. In each panel there are three pairs of bars that represent the levels of responding on $\mathrm{T}+, \mathrm{L}+$, and TL - trials. For each pair, the left-hand bar shows the mean level for the usual training condition, and the righthand bar shows the mean level for the reversed condition.

Inspection of the top panel of Figure 6 reveals that responding in Group MK was largely unchanged when switched from MK801 to saline. Responding remained at around $32 \% \mathrm{CRs}$ on $\mathrm{T}+$ trials. For $\mathrm{L}+$ trials, responding decreased somewhat from a mean level of $41 \% \mathrm{CRs}$ to $26 \%$ CRs. Responding to the compound also showed a slight decrease from $49 \%$ CRs to $42 \%$ CRs. However, none of these differences were significant $\left[F_{\mathrm{s}}(1,13)=\right.$ $0.17,3.89$, and 0.48 , respectively, $p s>.05]$. Inspection of the individual subjects revealed no consistent pattern of changes. Five subjects showed decreases, and 3 subjects showed increases. The largest change was a mean drop of $45 \%$ in 1 subject; the other changes were all less than $20 \%$ in either direction.

In contrast, responding in Group SAL decreased substantially when they received MK801. Examination of the individual subjects revealed that all of them showed reductions in responding, particularly on $\mathrm{T}+$ and $\mathrm{L}+$ trials. The smallest reduction was $25 \%$; half of the subjects showed reductions greater than $50 \%$. Responding decreased most sharply on $\mathrm{T}+$ trials, which declined from $91 \%$ CRs to $22 \%$ CRs. Responding on $\mathrm{L}+$ trials decreased from $83 \%$ CRs to $45 \%$ CRs. Responding on $\mathrm{TL}$ - trials showed a smaller decrease, from $100 \%$ CRs to $76 \%$ CRs. Statistical analyses confirmed that the ob- 

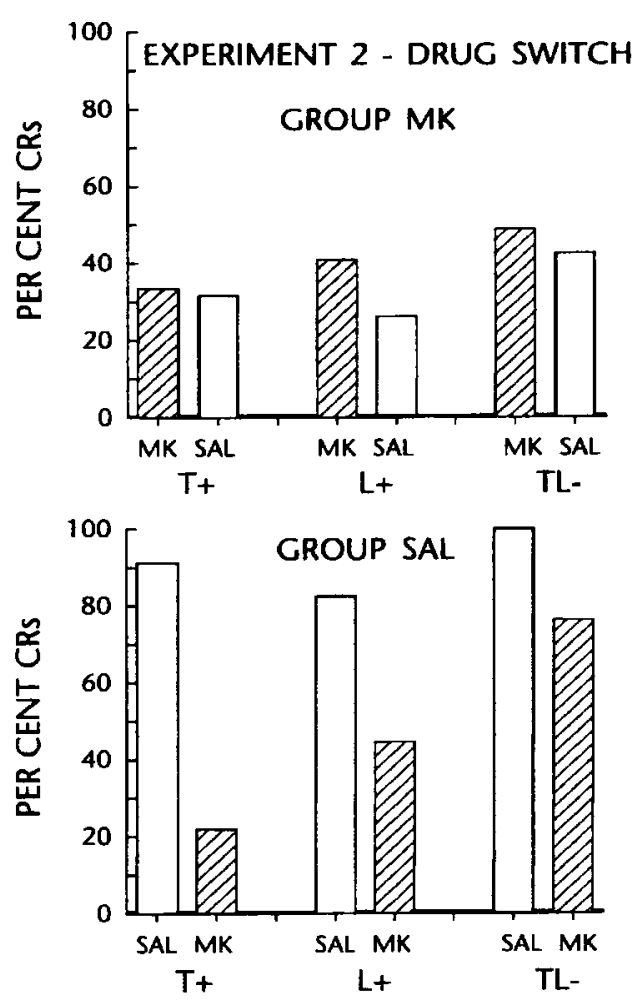

Figure 6. The effects of reversing the MK801 and saline injections in Experiment 2. There are three pairs of bars in each panel. From left to right, they show the mean percentage of CRs on $T+, L+$, and $T L-$ trials. For each pair, the left-hand bar shows the mean level for the usual training condition, and the righthand bar shows the mean level for the reversed condition.

served decreases in responding were significant $[F \mathrm{~s}(1,13)=166.20,21.39,5.62$, respectively, $p \mathrm{~s}<.05]$.

Summation effects. In Group SAL, responding on $\mathrm{TL}-$ trials appeared to resist the otherwise deleterious effects of MK801. To ascertain this resistance, we took advantage of the precise quantitative nature of summation in the rabbit NM preparation. Specifically, the probability of a CR to a test compound $(P c)$ can be predicted by the sum of the percentage CRs to the separate CSs $(P a, P b)$ as combined by the formula for statistically independent events_namely, $P a+P b-(P a \times P b)$ (Kehoe, 1982, 1986; Kehoe \& Graham, 1988; Kehoe, Horne, Horne, \& Macrae, 1994). The correlation between the actual and predicted responding to the compound has ranged from .68 to .99 , with a constant $5 \%$ underprediction.

For the present data, the statistical summation rule was applied to the performance of each subject on each day. During initial training on Days 3-10, responding on $\mathrm{TL}+$ trials was well predicted by the statistical sum of responding to the CSs. In Group MK, the correlation was $.98(n=8)$, and, as expected, actual responding on TLtrials $(M=35 \%$ CRs $)$ was slightly greater than the predicted responding from the $\mathrm{T}+$ and $\mathrm{L}+$ trials $(M=30 \%$ CRs). For Group SAL, the correlation was $.78(n=8)$, and actual responding on TL-trials ( $M=77 \% \mathrm{CRs})$ was again slightly greater than predicted responding $(M=$ $70 \%$ CRs). Across both groups, the $5 \%-7 \%$ underprediction was significant $[F(1,14)=5.79, p<.05]$. Any apparent differences between the groups were small, unsystematic, and nonsignificant.

In the drug-reversal tests, the replacement of MK801 with saline in Group MK had little impact on the relative levels of responding to the compound and the CSs. Specifically, responding on TL- trials under saline $(M=$ $42 \% \mathrm{CRs}$ ) was well predicted by summated responding from $\mathrm{T}+$ and $\mathrm{L}+$ trials $(M=41 \%)$. The subject-bysubject correlation was high and significant $(r=.89$, $n=8$ ).

In contrast to Group MK, Group SAL showed a large discrepancy between the actual and predicted levels of responding to the compound when saline was replaced by MK801. Under MK801, responding on TL trials in Group SAL declined $(M=76 \% \mathrm{CRs})$, but the predicted responding was even lower $(M=55 \% \mathrm{CRs})$ because responding on $\mathrm{T}+$ and $\mathrm{L}+$ trials declined so much. Statistical analyses confirmed that this discrepancy between actual and predicted responding was significant $[F(1,13)=16.77, p<.01]$. This discrepancy was systematic across subjects, and the subject-by-subject correlation remained very high $(r=.93, n=8)$. In summary, in Group SAL, the introduction of MK801 reduced responding to the individual CSs, but their compounding appeared to expose otherwise disrupted responding.

UR magnitude late in training. To determine whether any motor deficit was induced by MK801 over the course of training, the magnitude of the UR was examined on Days 15-17. During those days, both groups were returned to their original drug conditions. As was seen at the start of the experiment, Group MK showed slightly but not significantly smaller URs on US-alone trials than Group SAL. Their means were 5.9 and $6.9 \mathrm{~mm}$, respectively $[F(1,12)=1.91, p>.10]$. In Group MK, the UR magnitudes on $\mathrm{T}+$ and $\mathrm{L}+$ trials were slightly larger than those on US-alone trials $\left[M \mathrm{~s}=6.5\right.$ and $\left.6.4 ; F_{\mathrm{S}}<1\right]$. In Group SAL, the mean UR magnitudes on $\mathrm{T}+$ and $\mathrm{L}+$ trials were relatively small-2.8 and $4.9 \mathrm{~mm}$, respectively-which is significantly smaller than the UR magnitude on US-alone trials $\left[F_{\mathrm{S}}(1,12)=21.06,9.61, p<\right.$ $.01]$. This reduction in UR magnitude on CS-US trials compared with US-alone trials is an example of "conditioned diminution" that occurs as a CS gains associative strength (Donegan \& Wagner, 1987).

CS intensity. On Day 18, both of the groups received test trials on which the intensity of the tone CS was raised from the training value of $94 \mathrm{~dB}$ to values of 99 and $104 \mathrm{~dB}$. Group MK showed a rise in CR percentage at the 104-dB value. For CS intensities of 94,99 , and $104 \mathrm{~dB}$, the mean $\mathrm{CR}$ percentages were $43 \%, 43 \%$, and $61 \%$ CRs, respectively. Examination of the 7 individual subjects revealed that, across CS intensities, only 2 showed a large rise in responding. Both of those subjects had shown previous evidence of $\mathrm{CR}$ acquisition. For $\mathrm{T}+$ trials on Day 18 , they showed $17 \%$ and $63 \%$ CRs, re- 
spectively. Among the remaining subjects, 2 showed no responding, 2 always showed $100 \% \mathrm{CRs}$, and 1 always showed a moderate level of responding around $70 \%$ CRs. Statistical comparisons revealed a linear increase across intensities, which approached significance $[F(1,12)=3.52, p<.10]$ plus significant curvilinearity $[F(1,12)=5.79, p<.05]$. In the case of Group SAL, there was a ceiling effect. Across CS intensities, mean CR percentages were $96 \%, 100 \%$, and $95 \%$ CRs, respectively. The small differences were not significant.

\section{Discussion}

The results of Experiment 2 confirmed and extended the results of Experiment 1. First, MK801 failed to have a substantial or significant effect on UR magnitude when measured at both the beginning and end of training. Second, MK801 had a deleterious effect on CR acquisition and CR performance for light CSs as well as tone CSs. Thus, the effects of MK801 are not peculiar to auditory stimuli. Third, the combination of the tone and light CSs did not expose any otherwise subthreshold associative strength, but did reveal that responding in Group MK obeyed the same summation rule as seen in the control animals and in previous studies. Fourth, in Group SAL, the introduction of MK801 disrupted the usual summative relation. That is, responding on the TL-trials was significantly greater than predicted from responding on $\mathrm{T}+$ and $\mathrm{L}+$ trials. Fifth, late in training, the UR magnitude on CS-US trials was much the same as it was on US trials for Group MK. Group SAL, however, showed a smaller UR on CS-US trials than on US-alone trials. The lack of "conditioned diminution" in Group MK is further evidence for the lack of any subthreshold associative strength in Group MK. Sixth, in Group MK, increases in CS intensity produced an increase in CR likelihood at the 104-dB level, but only in 2 subjects that had already shown some $\mathrm{CR}$ acquisition.

\section{GENERAL DISCUSSION}

Much of the interest surrounding MK801 is that it may impair the processes of synaptic plasticity that are thought to underlie associative learning. However, other behavioral consequences of MK801 have made it difficult to determine the extent of its effect on learning. In both the present and previous experiments, MK801 had substantial deleterious effects on CR acquisition and performance, but the pattern of the data does not point uniquely to a disruption in the associative process. As will be detailed below, the most parsimonious interpretation is that MK801 disrupted processing of the CS within the conditioning pathways.

To see more clearly where MK 801 may be having its disruptive effects, the present behavioral findings can be related to the known neural pathways in the rabbit NM preparation (Thompson, 1986, 1990). There are separate circuits for the unconditioned reflex and the conditioned reflex. The pathway for the unconditioned reflex (US-UR) entails a short arc that runs from tactile trigeminal inputs through the brain stem to motor neurons in the accessory abducens (e.g., Cegavske, Harrison, \& Torigoe, 1987). Pathways subserving the acquisition of the conditioned reflex run through the brain stem and cerebellum (e.g., Steinmetz, Lavond, \& Thompson, 1989; Thompson, 1990). These pathways can be divided into three segments. First, there is an input segment for CSs that projects from sensory nuclei into the pontine nuclei and hence through mossy fibers to the cerebellar cortex (lobule HVI) and deep nuclei (lateral anterior interpositus). Second, there is a separate input segment for the US that consists of somatosensory projections to the dorsal inferior olive and its climbing fiber projections to the cerebellar cortex (HVI) and interpositus nucleus. Third, there is an output segment for the CR that originates in the interpositus nucleus and descends through the red nucleus and ultimately to motor neurons of the accessory abducens (e.g., Chapman, Steinmetz, \& Thompson, 1988; Rosenfield, Davydaitis, $\&$ Moore, 1985). In the rabbit NM preparation, both the $\mathrm{CR}$ and UR have a final common pathway in motor neurons of the accessory abducens nucleus (Berthier \& Moore, 1983; Disterhoft, Quinn, \& Weiss, 1987).

There is a lingering controversy as to whether the brain-stem-cerebellar pathways are the necessary and sufficient pathways for delay conditioning (e.g., Nordholm, Lavond, \& Thompson, 1991; Welsh \& Harvey, 1989; Yeo \& Hardiman, 1992). Certainly other circuits, most notably in the hippocampus, play a role in more complex conditioning phenomena (e.g., G. T. Berger, Berry, \& Thompson, 1986; Moyer, Deyo, \& Disterhoft, 1990; Schmajuk \& Moore, 1988). Nevertheless, the division between the pathways for the US-UR and CS-CR appears to be well established. Furthermore, the division between CS, US, and CR segments of the conditioning pathways appears to be a useful conceptual tool for identifying the sites of action for MK801.

First, consider the US-UR pathway. In the present findings, the measures of the UR failed to show any disruption by $M K 801$, even for very weak intensities of the shock US. However, for an airpuff US, G. B. Robinson and his associates have observed that MK801 reduced the magnitude of the UR across the full range of US intensities (G. B. Robinson, 1993; G. B. Robinson et al., 1993). Because the NM response is the same but the USs are different, MK801 may have its effect on the afferent arm of the reflex rather than on its efferent arm. That is, sensory processing of the airpuff to the cornea may be more susceptible to disruption than the processing of the electrical stimulation delivered subcutaneously through the wound clips. Similarly, the loss of motor coordination caused by MK801 in the rabbit and other species (see G. B. Robinson \& Reed, 1992) may arise from an impairment in the sensory processing of subtle proprioceptive and kinesthetic feedback rather than from a motor deficit as such.

It is more difficult to identify where in the three segments of the conditioning pathways MK801 is having its effect. However, some progress can be made. The pre- 
sent results point more toward a disruption of the CS input segment and less to the CR or US segments. This conclusion rests particularly on the pattern of results surrounding the switch in drug conditions. In the MK groups of both experiments, removal of MK801 produced little change in the low likelihood of CRs. If the disruption had been confined to the CR output segment, then the removal of MK801 in the MK groups should have resulted in an immediate rise in CR likelihood, similar in scale to the massive reduction seen when MK801 was introduced to the control groups. In other words, if MK801 affected only CR output, switching the drug conditions should have caused a symmetric switchover in CR performance in the MK groups versus the control groups. The pattern of results in the drug switch is also inconsistent with what would happen if MK801 disrupted the US input. If MK801 had disrupted only the US input, then the introduction of MK801 to control groups would have produced a slow extinction of CRs, but not the immediate and large drop in responding that was actually seen.

Elimination of the CR and US segments leaves the CS segment of the conditioning pathways as the final candidate for the site of MK801's disruptive effect. Within that segment, there are two points at which MK801 could intervene. First, MK801 could disrupt the neural encoding of the CS (e.g., Morris et al., 1990). Second, MK801 could disrupt the plastic changes in the NMDA receptors that receive the convergent inputs from the CS and US.

The pattern of present data favors the first hypothesisthat is, MK801 disrupts CS input before it reaches the site of plasticity. In the MK groups, there was a reduction in CR acquisition under the influence of MK801 and continued low levels of responding when the MK801 was removed. By themselves, these findings could be used to support either hypothesis. However, the control groups provide the differentiating evidencetheir profound and immediate reduction in CR likelihood when MK801 was introduced and their equally rapid recovery when it was removed. Having eliminated the CR segment as the site of this reduction, a disruption in CS input by MK801 is the only plausible alternative.

The present conclusion about the disruptive effect of MK801 on CS input is bolstered by the results of compounding the tone and light CSs on TL- trials in Experiment 2. In Group MK, responding on TL- trials in training followed the same summation rule as in Group SAL. By itself, this finding indicates only that MK801 did not grossly distort the expression of associative strength in CR performance by, for example, raising the threshold for triggering the CR. However, when MK801 was given to Group SAL, responding to TLwas substantially higher than predicted from statistical summation of the reduced level of responding on $\mathrm{T}+$ and $\mathrm{L}+$ trials. This disproportionately high level of responding on TL- trials indicates that the established associative linkages could be activated when there was enough sensory input to surmount the disruption to CS input caused by MK801.
In a similar manner, the findings from increasing CS intensity in Group MK of Experiment 2 also suggest that MK801 was disrupting CS input. Both of the animals that showed an increase in responding as CS intensity rose had also previously displayed low but appreciable levels of CR acquisition to both tone and light. These findings suggest that MK801 was not obliterating CS input. That is to say, an intense CS overcame the disruptive influence of MK801 and activated whatever associative strength had been acquired by those 2 animals. However, in the animals that had shown no evidence of $\mathrm{CR}$ acquisition, increasing the CS intensity failed to reveal any evidence of hidden associative strength.

Both the resistance of responding on TL- trials to the otherwise deleterious effects of MK801 in Group SAL and the increase in responding in Group MK as a function of CS intensity help to reconcile the present findings with previous findings - that MK801 more directly disrupted associative processes. MK801 has impaired, for example, the acquisition but not the expression of responses in instrumental tasks, such as a radial-arm maze task (Shapiro \& Caramanos, 1990) and passive avoidance in mice (Benvenga \& Spaulding, 1988). In these cases, the learned cues for responding may have been more like a compound of several stimuli and less like the discrete tone and light events used as CSs in the present experiments. Certainly, in the instrumental tasks, there were multiple sources of cues that could have been combined during training to overcome a reduction in the salience of individual stimuli caused by MK801. Accordingly, the use of a compound of CSs and/or more intense CSs on training trials may provide a means for minimizing MK801's disruption of CS input and hence reveal any effect it has on associative learning.

In attempting to assess the disruptive effects of MK801 on CS inputs, it would have been convenient if the results of presenting the CS prior to the US on Day 2 had been more conclusive. In Experiment 2, Group SAL showed some facilitation of the UR by the tone CS, and Group MK did not. This difference is consistent with the hypothesis that MK801 disrupts the CS input. However, it would be unwise to place much confidence in this difference when placed against failures to see facilitation of the UR in the control groups by either the light CS in Experiment 2 or the tone CS in Experiment 1. Furthermore, facilitation of the UR by the CS may depend on pathways other than the conditioning pathways (Nowak \& Gormezano, 1990; Weisz \& LoTurco, 1988).

As with all inferences about neural or conceptual processes derived from behavioral observations, some caution must be exercised. In the present case, two warnings are in order. First, at a neural level, it would be a mistake to pretend that the present results point to a specific neuroanatomical pathway for the action of MK801. Although the present results point broadly to the CS input pathways, they do not point explicitly to the cerebellar mossy fibers. There are plausible possibilities outside the primary conditioning pathways. For example, Berry and Thompson (1979) found that disruption of af- 
ferent inputs to the hippocampus through lesions of the medial septal nuclei impairs CR acquisition in the rabbit NM preparation. Second, at the conceptual level, the present results do not preclude the possibility that MK801 may impair the formation of associations and/or the operation of the US input pathways. Disruption of the CS input makes it difficult to detect whether or not MK801 has other modes of action. As mentioned previously, the use of multiple CSs or perhaps more intense CSs during training may unmask effects of MK801 on the formation of associations. Alternatively, there is unpublished evidence that a lower dose (e.g., $.05 \mathrm{mg} / \mathrm{kg}$ ) yields a more selective impairment in associative learning in the rabbit NM preparation ( $\mathrm{L}$. T. Thompson, personal communication, November 8,1993 ).

Although disruption of CS input is the most parsimonious explanation of the present data, there are more complex hypotheses that can also explain the major findings. The simplest of these alternatives would entail two factors. First, the decremental effects of MK801 on $\mathrm{CR}$ acquisition in the MK groups may reflect deficits in associative learning. Second, the decremental effects of introducing MK801 after the establishment of the CR in the control groups may reflect state-dependent learning-specifically, a generalization decrement in responding when a novel internal stimulus context was produced by MK801. In studies using multiple training trials, rats have acquired discriminative behavior using the presence versus absence of MK801 as the discriminative cue (Tricklebank, Singh, Oles, Preston, \& Iversen, 1989). A state-dependency hypothesis can also explain the resistance of responding on TL trials to the otherwise deleterious effects of MK801 in Group SAL. Specifically, the TL compound may have provided sufficient stimulus support to activate the underlying associations in the face of the novel MK801-induced context.

There is some weak evidence against a statedependency hypothesis in the present findings. If statedependency effects are symmetrical, then the animals in the MK groups that had shown CR acquisition to a substantial degree should have shown an immediate drop in responding when MK801 was removed. In fact, changes in responding were modest and in opposite directions across the two experiments and across individual subjects within each experiment.

\section{REFERENCES}

Benvenga, M. J., \& Spaulding, T. C. (1988). Amnesic effect of the anticonvulsant MK-801. Pharmacology, Biochemistry \& Behavior, 30, 205-208.

BERGER, T. W. (1984). Long-term potentiation of hippocampal synaptic transmission affects rate of behavioral learning. Science, 224, 627-630.

Berger, T. W., Berry, S. D., \& Thompson, R. F. (1986). Role of the hippocampus in classical conditioning of aversive and appetitive behaviors. In R. L. Isaacson \& K. H. Pribram (Eds.), The hippocampus (Vol. 4, pp. 203-240). New York: Plenum.
Berry, S. D., \& Thompson, R. F. (1979). Medial septal lesions retard classical conditioning of the nictitating membrane response in rabbits. Science, 200, 1298-1300.

Berthier, N. E., \& MoOre, J. W. (1983). The nictitating membrane response: An electrophysiological study of the abducens nerve and nucleus and the accessory abducens nucleus in rabbit. Brain Research, 258, 201-210.

Cegavske, C. F., Harrison, T. A., \& Torigoe, Y. (1987). Identification of the substrates of the unconditioned response in the classically conditioned, rabbit, nictitating-membrane preparation. In I. Gormezano, W. F. Prokasy, \& R. F. Thompson (Eds.), Classical conditioning (pp. 65-91). Hillsdale, NJ: Erlbaum.

Chapman, P. F., Steinmetz, J. E., \& Thompson, R. F. (1988). Classical conditioning does not occur when direct stimulation of the red nucleus or cerebellar nuclei is the unconditioned stimulus. Brain Research, 442, 97-104.

Coleman, S. R., \& Gormezano, I. (1971). Classical conditioning of the rabbit's (Oryctolagus cuniculus) nictitating membrane response under symmetrical CS-US interval shifts. Journal of Comparative \& Physiological Psychology, 77, 447-455.

Collingridge, G. L., Kehl, S. J., \& McLennan, H. (1983). Excitatory amino acids in synaptic transmission in the Schaffer collateralcommissural pathway of the rat hippocampus. Journal of Physiology, 334, 33-46.

COTMAN, C. W., \& IVERSEN, L. L. (1987). Excitatory amino acids in the brain: Focus on NMDA receptors. Trends in Neuroscience, 10, 263-265.

Disterhoft, J. F., Quinn, K. J., \& Weiss, C. (1987). Analyses of the auditory input and motor output pathways in rabbit nictitating membrane conditioning. In I. Gormezano, W. F. Prokasy, \& R. F. Thompson (Eds.), Classical conditioning (pp. 93-116). Hillsdale, NJ: Erlbaum.

Donegan, N. H., \& WaGNER, A. R. (1987). Conditioned diminution and facilitation of the UR: A sometimes opponent-process interpretation. In I. Gormezano, W. F. Prokasy, \& R. F. Thompson (Eds.), Classical conditioning (pp. 339-369). Hillsdale, NJ: Erlbaum.

GABRIEL, M. (1988). An extended laboratory for behavioral neuroscience: A review of Classical Conditioning (third edition). Psychobiology, 16, 79-81.

GilberT, M. E., \& MACK, C. M. (1990). The NMDA antagonist MK-801 suppresses long-term potentiation, kindling and kindlinginduced potentiation in the perforant path of the unanesthetized rat. Brain Research, 519, 89-96.

GoRmezano, I. (1966). Classical conditioning. In J. B. Sidowski(Ed.) Experimental methods and instrumentation in psychology (pp. 385420). New York: McGraw-Hill.

Gormezano, I., \& GibBs, C. M. (1988). Transduction of the rabbit's nictitating membrane response. Behavior Research Methods, In struments, \& Computers, 20, 18-21.

Gormezano, I., \& HaRvey, J. A. (1980). Sensory and associative effects of LSD in classical conditioning of rabbit (Oryctolagus cuniculus) nictitating membrane response. Journal of Comparative \& Physiological Psychology, 94, 641-649.

Gormezano, I., Kehoe, E. J., \& Marshall, B. S. (1983). Twenty years of classical conditioning research with the rabbit. In J. M. Sprague \& A. N. Epstein (Eds.), Progress in psychobiology and physiological psychology (pp. 197-275). New York: Academic Press.

Gormezano, I., Thompson, R. F., \& Prokasy, W. F. (Eds.) (1987). Classical conditioning III. Hillsdale, $\mathrm{NJ}$ : Erlbaum.

Harvey, J. A., \& Gormezano, I. (1981). Effects of haloperidol and pimozide on classical conditioning of the rabbit nictitating membrane response. Journal of Pharmacology \& Experimental Therapeutics, 218, 712-718.

HaRvey, J. A., \& GoRmezano, I., \& COOL, V. A. (1982). Effects of $d$ lysergic acid diethylamide, $d$-2-bromolysergic acid diethylamide, $d l$ dimethoxy-4-methylamphetamine and $d$-amphetamine on classical conditioning of the rabbit nictitating membrane response. Journal of Pharmacology \& Experimental Therapeutics, 221, 289-294.

Harvey, J. A., Gormezano, I., \& CoOl-Hauser, V. A. (1983). Effects 
of scopolamine and methylscopolamine on classical conditioning of the rabbit nictitating membrane response. Society for Neuroscience Abstracts, 9, 330.

Harvey, J. A., Gormezano, I., Cool-Hauser, V. A., \& Schindler, C. W. (1988). Effects of LSD on classical conditioning as a function of CS-UCS interval: Relationship to reflex facilitation. Pharmacology, Biochemistry \& Behavior, 30, 433-441.

Heale, V., \& HARLEY, C. (1990). MK-801 and AP5 impair acquisition, but not retention, of the Morris milk maze. Pharmacology, Biochemistry \& Behavior, 36, 145-149.

Hebs, D. O. (1949). The organization of behavior. New York: Wiley.

KEHOE, E. J. (1982). Overshadowing and summation in compound stimulus conditioning of the rabbit's nictitating membrane response. Journal of Experimental Psychology: Animal Behavior Processes, 8, 313-328.

KEHOE, E. J. (1986). Summation and configuration in conditioning of the rabbit's nictitating membrane response to compound stimuli. Journal of Experimental Psychology: Animal Behavior Processes, 12, 186-195.

Kehoe, E. J., \& Graham, P. (1988). Summation and configuration in negative patterning of the rabbit's conditioned nictitating membrane response. Journal of Experimental Psychology: Animal Behavior Processes, 14, 320-333.

Kehoe, E. J., Horne, A. J., Horne, P. S., \& Macrae, M. (1994). Summation and configuration between and within sensory modalities in classical conditioning of the rabbit. Animal Learning \& Behavior, 22, 19-26.

KEITH, J. R., \& RUDY, J. W. (1990). Why NMDA-receptor-dependent long-term potentiation may not be a mechanism of learning and memory: Reappraisal of the NMDA-receptor blockade strategy. Psychobiology, 18, 251-257.

KemP, J. A., Foster, A. C., \& WoNG, E. H. F. (1987). Non-competitive antagonists of excitatory amino acid receptors. Trends in Neuroscience, 10, 294-298.

Lynch, M. A., Errington, M. L., Clements, M. P., Bliss, T. V. P., Redini-Del Negro, C., \& Laroche, S. (1990). Increases in glutamate release and phosphoinositide metabolism associated with long-term potentiation and classical conditioning. Progress in Brain Research, 83, 251-256.

Marshall-Goodell, B., Kehoe, E. J., \& Gormezano, I. (1992). Laws of the unconditioned reflex in the rabbit nictitating membrane preparation. Psychobiology, 20, 229-237.

Marshall-Goodell, B., Schreurs, B. G., \& Gormezano, I. (1982). Ruler vs. the Apple II/FIRST system analysis of analog signals in classical conditioning. Behavior Research Methods \& Instrumentation, 14, 519-525.

Morris, R. G. M., Davis, S., \& Butcher, S. P. (1990). Hippocampal synaptic plasticity and $\mathrm{N}$-methyl-D-aspartate receptors: A role in information storage. Philosophical Transactions of the Royal Society of London, 329, 187-204.

Moyer, J. R., Deyo, R. A., \& Disterhoft, J. F. (1990). Hippocampectomy disrupts trace eye-blink conditioning in rabbits. $B e$ havioral Neuroscience, 104, 243-252.

Muller, D., JOLY, M., \& LyNCH, G. (1988). Contributions of quisqualate and NMDA receptors to the induction and expression of LTP. Science, 242, 1694-1697.

Nordholm, A. F., LAvond, D. G., \& Thompson, R. F. (1991). Are eyeblink responses to tone in the decerebrate, decerebellate rabbit conditioned responses? Behavioural Brain Research, 44, 27-34.

NowaK, A. J., \& GoRMEZANO, I. (1990). Electrical stimulation of brainstem nuclei: Elicitation, modification, and conditioning of the rabbit nictitating membrane response. Behavioral Neuroscience, 104, 4-10.

Parada-TursKa, J., \& TURSKI, W. A. (1990). Excitatory amino acid antagonists and memory: Effect of drugs acting at N-methyl-Daspartate receptors in learning and memory tasks. Neuropharmacology, 29, 1111-1116.

RoBINSON, G. B. (1993). MK801 retards acquisition of a classically conditioned response without affecting conditioning-related alterations in perforant path-granule cell synaptic transmission. Psychobiology, 21, 253-264.

Robinson, G. B., Port, R. L., \& Stillwell, E. (1993). Latent inhibi- tion of the classically conditioned rabbit nictitating membrane response is unaffected by NMDA antagonist MK801. Psychobiology, 21, 120-124.

Robinson, G. B., \& REed, G. D. (1992). Effect of MK-801 on the induction and subsequent decay of long-term potentiation in the unanesthetized rabbit hippocampal dentate gyrus. Brain Research, 569, 78-85.

Robinson, G. S., JR., Crooks, G. B., JR., Shinkman, P. G., \& GalLAGHER, M. (1989). Behavioral effects of MK-801 mimic deficits associated with hippocampal damage. Psychobiology, 17, 156-164.

Rosenfield, M. E., Davydaitis, A., \& Moore, J. W. (1985). Brachium conjunctivum and rubrobulbar tract: Brainstem projections of red nucleus essential for the conditioned nictitating membrane response. Physiology \& Behavior, 34, 751-759.

SCANDRETT, J., \& GoRMEZANO, I. (1980). Microprocessor control and A/D data acquisition in classical conditioning. Behavior Research Methods \& Instrumentation, 12, 120-125.

Schindler, C. W., Gormezano, I., \& Harvey, J. A. (1984). Sensory and associative effects of morphine and naloxone in classical conditioning of the rabbit nictitating membrane response. Psychopharmacology, 83, 114-121.

SCHMAJUK, N. A., \& Moore, J. W. (1988). The hippocampus and the classically conditioned nictitating membrane response: A real-time attentional-associative model. Psychobiology, 16, 20-35.

Shapiro, M. L., \& Caramanos, Z. (1990). NMDA antagonist MK-801 impairs acquisition but not performance of spatial working and reference memory. Psychobiology, 18, 231-243.

Steinmetz, J. E., Lavond, D. G., \& Thompson, R. F. (1989). Classical conditioning in rabbits using pontine nucleus stimulation as a conditioned stimulus and inferior olive stimulation as an unconditioned stimulus. Synapse, 3, 225-233.

Thompson, R. F. (1976). The search for the engram. American Psychologist, 31, 209-227.

Thompson, R. F. (1986). The neurobiology of learning and memory. Science, 233, 941-947.

Thompson, R. F. (1990). Neural mechanisms of classical conditioning in mammals. Philosophical Transactions of the Royal Society of London: Series $B, 329,161-170$.

Tricklebank, M. D., Singh, L., Oles, R. J., Preston, C., \& Iversen, S. D. (1989). The behavioural effects of MK-801: A comparison with antagonists acting noncompetitively and competitively at the NMDA receptor. European Journal of Pharmacology, 167, 127 135.

Trujillo, K. A., \& AKIL, H. (1991). Inhibition of morphine tolerance and dependence by the NMDA receptor antagonist MK-801. Science, 251, 85-87.

Venable, N., \& Kelly, P. H. (1990). Effects of NMDA receptor antagonists on passive avoidance learning and retrieval in rats and mice. Psychopharmacology, 100, 215-221.

Weisz, D. J., ClaRK, G. A., \& Thompson, R. F. (1984). Increased responsivity of dentate granule cells during nictitating membrane response conditioning in the rabbit. Behavioural Brain Research, 12, 145-154.

Weisz, D. J., \& LoTurco, J. J. (1988). Reflex facilitation of the nictitating membrane response remains after cerebellar lesions. Behavioral Neuroscience, 102, 203-209.

Welsh, J. P., \& HaRVEY, J. A. (1989). Cerebellar lesions and the nictitating membrane reflex: Performance deficits of the conditioned and unconditioned response. Journal of Neuroscience, 9, 299-311.

WroBlEWSKI, J. T., \& DANYSZ, W. (1989). Modulation of glutamate receptors: Molecular mechanisms and functional implications. Annual Review of Pharmacology \& Toxicology, 29, 441-474.

XU, X., \& DAvIS, R. E. (1992). N-methyl-D-aspartate receptor antagonist MK-801 impairs learning but not memory fixation or expression of classical fear conditioning in goldfish (Carassius auratus). Behavioral Neuroscience, 106, 307-314.

Yeo, C. H., \& HaRdiman, M. J. (1992). Cerebellar conditioning and eyeblink conditioning: A reexamination. Experimental Brain Research, 88, 623-638.

(Manuscript received June 30, 1993; revision accepted for publication December 17, 1993.) 